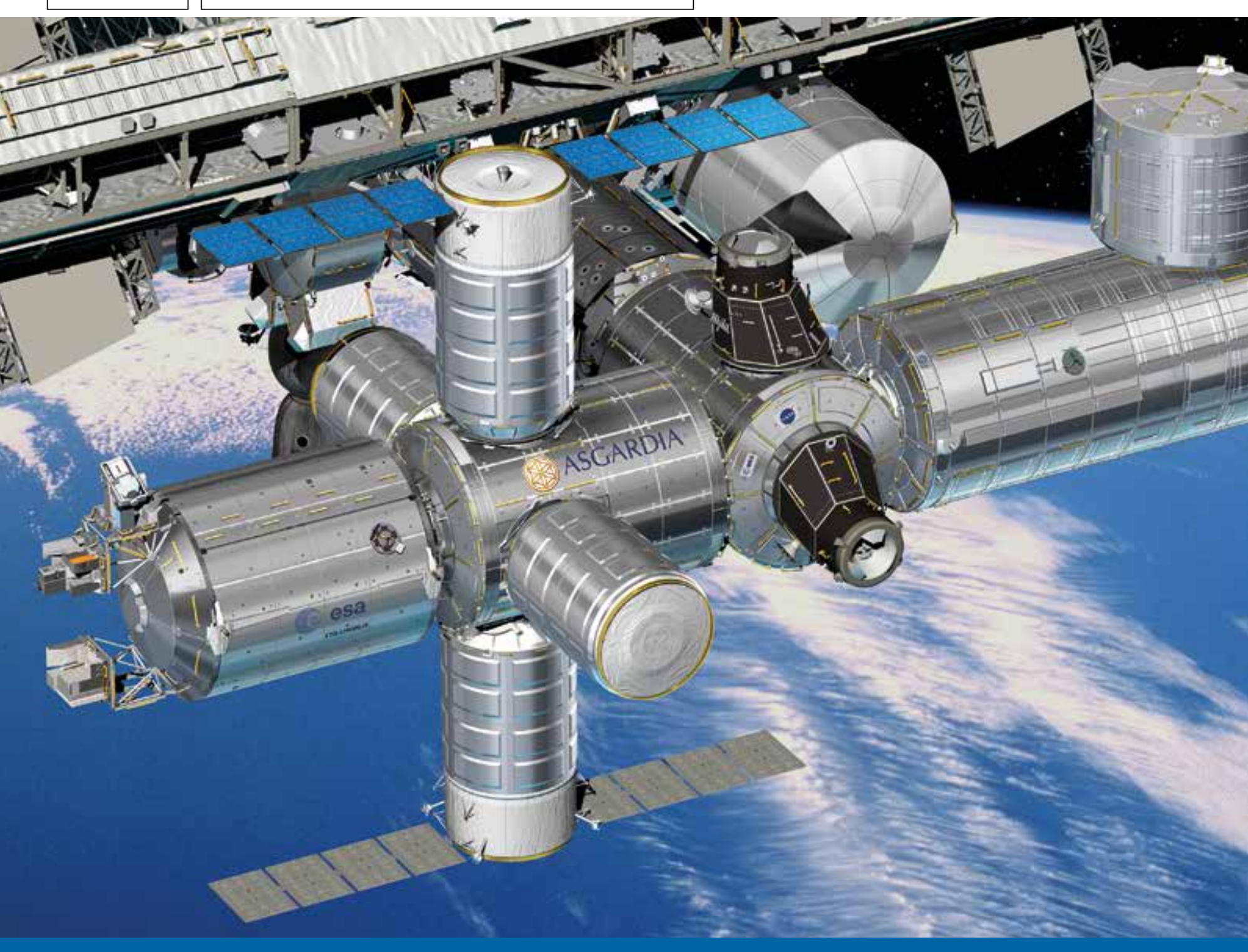

\section{Asgardia's project for a new module to expand Space Station}

\section{Проект узлового модуля «Асгардия» для Международной космической станции}

Статья «Asgardia's Project for a New Module to Expand Space Station» опубликована в международном аэр

Перевод с английского языка А. Рудневой
ХХудожественная реконструкция
узлового модуля «Асгардия» в месте предполагаемой локализации (справа от отсека Columbus EKA) на MKC

ABSTRACT I Private sector involvement in the International Space Station (ISS) is becoming increasingly important as commercial organisations provide services and hardware to enhance the orbital operations of the Space Station which, in November 2020, marked two decades of continuous occupation. During the first Asgardia Space Science \& Investment Conference, held in Germany in October 2019, a project to add a new commercially procured docking module to the ISS was announced as a key step to expanding the
permanent human presence in low Earth orbit. Dr Igor Ashurbeyli, General Designer, provides a technical overview of the project and the industrial partnership arranged to deliver it.

Keywords: International Space Station (ISS), "Asgardia" Module, low-Earth orbit, economics, space exploration

АНноТАЦИЯ I Вклад частных компаний в работу Международной космической станции приобретает все большее значение - они предоставляот новые услуґи и оборудование, тем Самым Стимулируя дальнейшее развитие МКС, которая в 2020 году отметила двадцатилетие непрерывной эксплуатации.

Проект по присоединению к МКС нового узлового модуля назвали главным шагом к расширению постоянного присутствия человека на низкой околоземной орбите. Это произошло на I Научно-инвестиционном конгрессе Асгардии, состоявшемся в Германии в октябре 2019 года.

Генеральный конструктор проекта Игорь Рауфович Ашурбейли представляет технический обзор узлового модуля и рассказывает о промышленном партнерстве, учреждаемом для осуществления проекта. Ключевые слова: Международная космическая станция (МКC), узловой модуль «Асгардия», низкая околоземная орбита (НОО), экономика, исследования в космосе

Узловой модуль первый шаг к автономной космической станции За последние 10 лет неоднократно поднимался вопрос о дальней те (НОO) по окончании срока спужбы МKC. В настояше время предполагается, что эксплуатация станции продлится примерно до 2озо года. Тем не менее очевидно, ч в существующем виде она не может работать столь продожительно

Национальное управление по аэронавтике и исследостранста (HACA) уак ший партнер MKC выступает инициатором программы коммерческого использоварой Станции, в рамках которай операции и обстуживание передается частным компа ниям. Программа действий аявленная в июне 2019 года, включает в себя пять ключевых аспектов: формирова ние основ коммерческого использования MKC и ценово цессов коммерческого развицесов коммерческого развидля стимулирования устойчи

Существующая стандартная конструкция МКС обеспечивает жизнедеятельность экипажей до семи человек, в этой связи увеличение численности экипажа потребует дополнительных помещений. вого спроса, количественная оценка долгосрочных потребости на $\mathrm{HOO}$.

Благодаря этой программе Национальная паборатория США, управляюшая американским сегментом космической станции, получила частные инвестиции для расширения возможностей МКС: от малого лабораторного оборудова-

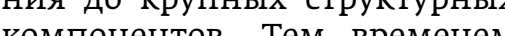
компонентов. Тем временем МКС вилючились в разработку

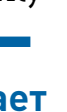




\section{MKC}

Международная

ктанция
стан

Служебный
модуль (СМ)

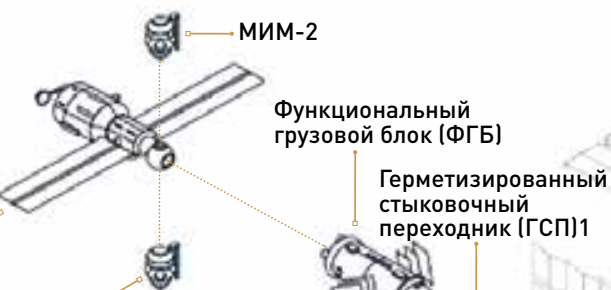

EMTM 3

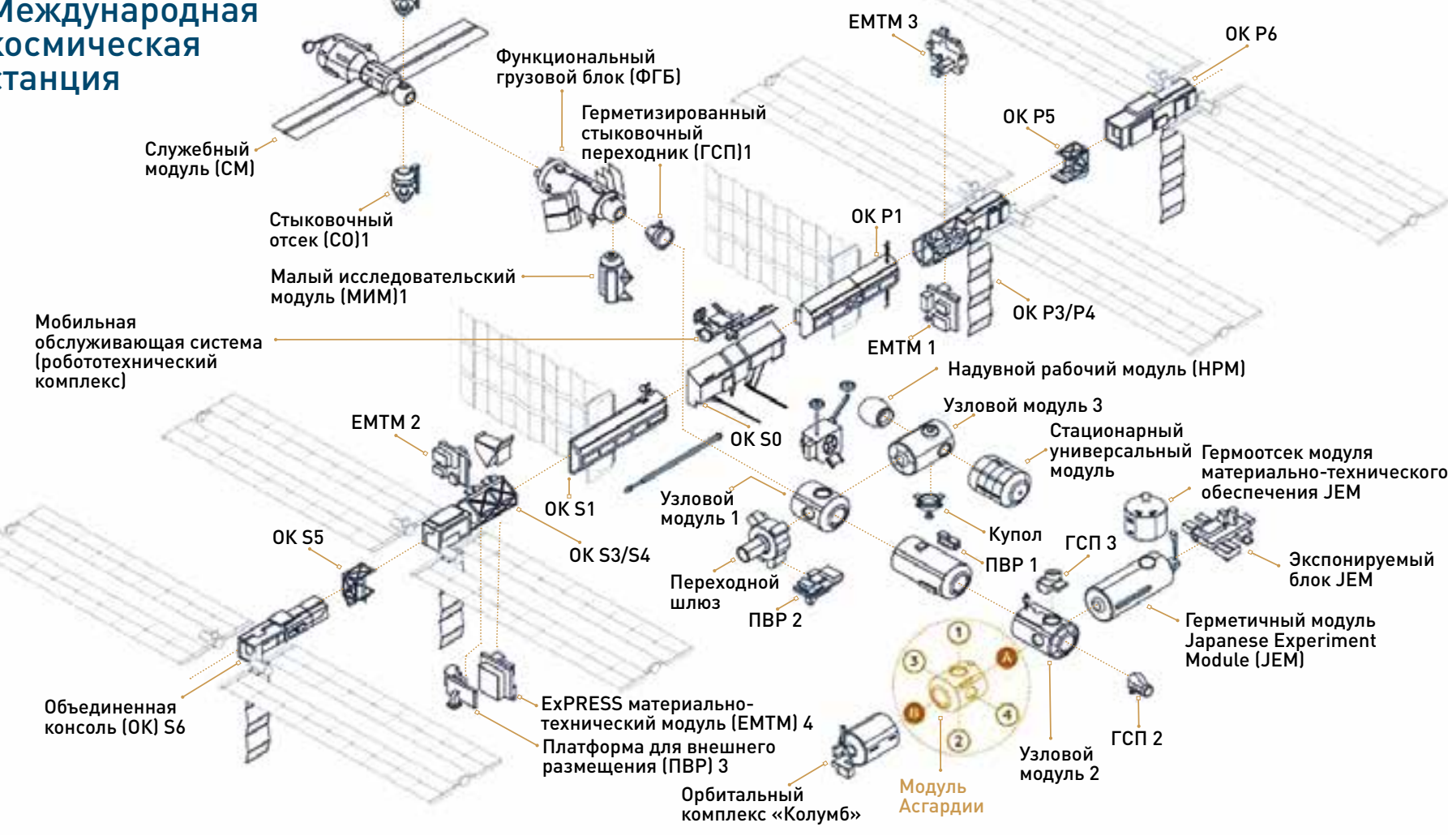

$\Delta$ Международная космическая станция. Планируемое месторасположение

узлового модуля «Асгардия» в общей архитектуре МКС

\section{Точки пересечения проекта узлового модуля «Асгардия» с новой стратегией ЕКА по исследованию космоса}

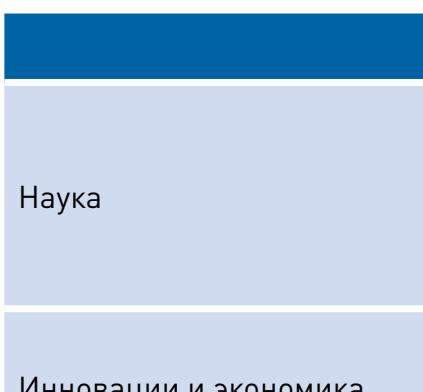

ОПРЕДЕЛЕНИЕ

Закрепление передового европейского опыисследований и разработки современного оборудования

Содействие конкурентоспособности и росту европейского промышленного сектора, расширение границы технологических знаний в
других областях хозяйственной деятельности Создание глобальной основы для сотрудничества с целью выполнения проектов в сфере освоения космоса, при участии общечеловеческих целей

Привлечение общества в целом и молодого поколения в частности к расширению своих ных и точных наук, к пониманию ценностей ґлобального сотрудничества в космосе, Включая подготовку к широкому и уверенному
присутствию человека в Солнечной системе

\section{ДОПОЛНИТЕЛЬНЫЕ ПРЕИМУЩЕСТВА}

Узловой модуль «Асгардия» придаст до-

полнительный стимул научно-техническому конструкция привлечет частные инвестиции задач

Тщательный подбор материально-технической базы стимулирует создание инновационных услуг и продуктов

Асгардия поддерживает международное сотрудничество через свое растущее сообщеностей, Коммерческий порход обеспечльрост национального участия

В настоящее время технологии, доступные мена разработки погрессивны, чем во вр Новый узловой модуль оснащается инструментами для простого и быстрого подключения к современным наземным устройствам
Ограниченное количество доступных стыковочных

портов и соответствующая им инфраструктура являются основным препятствием для расширения коммерческих возможностей МКС.

новой политики, направленной на расширение использования станции и ее объектов сторонними организациями, ми и странами, не вомпяния ми и сранами, не входящими Харахтерно, что эта новая комХерческая потитика не ограмчивается предоставтением инфраструктуры и оборудования, но отдает приоритет созданию новых возможностей для частных астронавтов. Такой подход представляет интерес для государств, которые ранее не име ли доступа $\mathrm{K}$ пилотируемым исследован к мы астронавтов ОАЭ и других инициатив, в числе которых программы космических полетов Индии, Турции и Нигерии.

Коммерциализация МКС

Существующая на сегодня стандартная конструкция MKC обеспечивает жизнедеятедьность экипажей до семи человек, поэтому увеличение численности экипажа потребует дополнительных помещений - как для научных

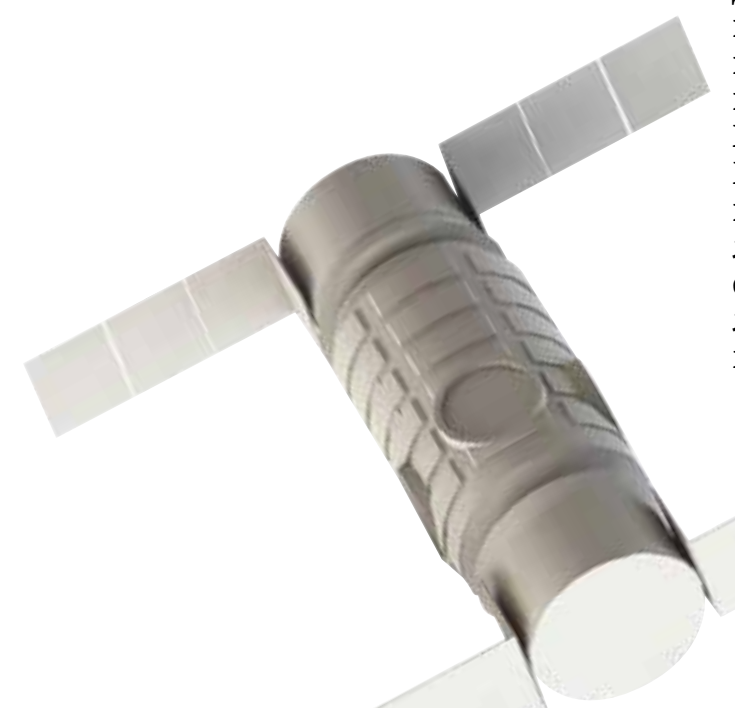

экспериментов и исследований, так и для работы, сна, гигиены, питания, развлечений и так далее. Очевидно, что это, в свою очередь, потребует увеличения чения.

Наиболее значительные примеры коммерческой деятельности по расширению МKC включают расширяемый мо-
дуль Bigelow, наружную целевую платформу для полезной нагрузки Bartolomeo от компаBishop Airlock от компании Nanoracks. Не так давно, в январе 2020 года, НАСА заключило с компанией Aхіоm контракт стоимостью 140 миллионов долларов на Строительскво жилого бото

4 Потенциальная дополнительная летная компоновка узлового присоединенными служебными отсеками для дальнейшего наращивания автономии после 作
Проект узлового модуля «Асгардия» полностью соответствует целям

стратегии ЕКА по освоению космоса.

нируется присоединить к MKC в 2024 году. Разработки такого НАCA успешно решает задачу коммерциализации МКС. Это происходит во многом благодаря тому, что НАСА отдает себе отчет: подобный подход позволит перенаправить финансирование на другие, более сложные рроекы, такие как ис

Эти примеры подтверждают необходимость коммерциали зации и, кроме того, привлекаограничениям МKC, в уастности к малому количеству доступных стыковочных узлов и люков. Входные порты являются главной перспективой расши рения МKC, как временно, так и на постоянной основе. 




Именно недостаточное количество доступных стыковочинфраструктуры является основным препятствием для расширения коммерческих возможностей МКС. Предложение по узловому модулю «Асгар-
дия», который интегрируетдия", который интегрирует ся в европейскую часть МКС, шить эту проблему.

зловой модуль Асгардии как для государст П в ответ на призыв Европейского Более того, проект полностью космического агентства (ЕKA) соответствует целям страте"Освоние ги ЕКА по освоению космоса, щая сила развития и конкурен- утвержденной в 2014 году. Эта тоспособности: возможности для стратегия охватывает четыре частного сектора». По сути, про- направления: научный проект Асгардии решает вопрос огра- гресс, инновационный потенниченного жилого пространства циал и экономический рост, и исследовательского потенциа- глобальное сотрудничество

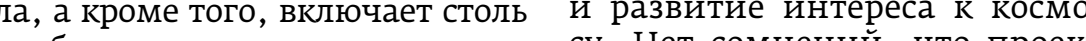

Задачи и участие основных партнеров

\begin{tabular}{|c|c|c|}
\hline ПАРТНЕР & ЗАДАЧИ & УЧАСТИЕ \\
\hline \multirow{3}{*}{$\begin{array}{l}\text { Европейское } \\
\text { космическое } \\
\text { агентство }\end{array}$} & $\begin{array}{l}\text { Обеспечение возможности доступа } \\
\text { на МКС }\end{array}$ & $\begin{array}{l}\text { Обеспечение долгосрочного содействия MKC } \\
\text { в отношении общей инфраструктуры и основ- } \\
\text { ных операций на остаточный срок службы MKC }\end{array}$ \\
\hline & $\begin{array}{l}\text { Организация взаимодействия с други- } \\
\text { ми партнерами МКС }\end{array}$ & $\begin{array}{l}\text { Долевое участие в качестве партнера в мон- } \\
\text { тажных работах }\end{array}$ \\
\hline & Гарантия и защита рынка & $\begin{array}{l}\text { Обеспечение регулярных маневров для } \\
\text { операций по стыковке прибывающих космиче- } \\
\text { ских аппаратов, в том числе вспомогательных } \\
\text { отсеков }\end{array}$ \\
\hline Асгардия & $\begin{array}{l}\text { Коммерчески ориентированные опе- } \\
\text { рации узлового модуля «Асгардия» }\end{array}$ & $\begin{array}{l}\text { Разработка миссии, создание и внедрение } \\
\text { узлового модуля «Асгардия» }\end{array}$ \\
\hline
\end{tabular}


по новому узловому модулю техническое развитие после разрабатывался с целью при- окончания срока эксплуатации мира, а также чтобы обеспе- ние предусматривает разработчить рабочие места и предло- ку узлового модуля на основе жить пути вывода европейской существующей орбитальной космической промышленно- инфраструктуры, созданной сти на новый уровень. европейской космической проКроме того, этот проект учи- мышленностью и финансирутывает прекращение деятель- емой на коммерческой основ ности MKС в рамках ее текущего в рамках государственно-част использования и закладывает ното парине са мала комосновы "дорожной карты” для и Европейским космическим мири низкой оволоземной орбиты. Несмотря на рекламную шумиху, другие предложения подобного рода отсутствуют.

Суть инициативы Асгардии агентством.

В минимальном объеме узловой модуль «Асгардия» предназначается:

- для обеспечения дополниформирование экономики тельных стыковочных портов промышленными, коммер- и, таким образом, возможческими и государственными ческих модулей от новых партнерами, в условиях кото- участников; нут одними из агентста станых клиентов. Кроме того, она соответствует долгосрочной цели Асгардии по созданию автономной космической инфра структуры на НОO, известной как «Земной ковчег Асгардии», чтобы обеспечить продолжение исследований и непрерывно потребностей европейских высокотехнологичных произ водств; народного и коммерческого партнерства.

Анализ возможных вариантов показывает, что наиболее ым и технически обоснованным решением явконструкции и бортовых систем уже разработанных модулей МКС. Кроме того, такой ционный дизайн позвол адиздать серию жилых отсеков для различных проектов и клиенпроизводства в сочетании с эффектом совместимости со стандартными серийно выпускае мыми ракетами-носителями. Без учета дополнительных стыковочных портов конфигурация будет соответствовать всем требованиям непрерывня Columbus, в настоли модумя состыкованного с портом на правом борту модуля Node-2 MKC. Анализ технической выполнимости показывает, что
- для обеспечения условий для ляется узловой модуль на базе тов при сниженной стоимости 

Члены консорциума Асгардию представляют три юридических лица, заре-
гистрированные в Австрии:

- НГО «Асгардия Терра Арк» (АТА) - неправитель-

ственная организация:

- АГ «Асгардия Файненшл Арк» (AFA) - акционерная компания;

- ГмбХ «Центр независимых исследований Асгардии» (AIRC) - частная компания, принадлежит

Компания Nanoracks-Europe

В 2009 году Nanoracks стала первой компанией, которая владеет собственным исследовательским

ках новаторского соглашения с НАСА, действующе го по сей день. Сейчас у Nanoracks есть клиенты более чем в 34 странах. При этом не позднее чем через пятт лет Nanoracks планирует стать одной из нескольких платформами.

Компания Thales

Alenia Space Italia (TAS-I)

Европейский лидер в области спутниковых систем

и орбитальной инфраструктуры, принадлежащий

Thales (67\%) и Finmeccanica (33\%), при этом совместно

c Telespazio образует Space Alliance - «космический
альянс». TAS-I является генеральным подрядчиком

большинства программ Итальянского космического

агентства (ASI) и некоторых крупных программ Европейроль во многих международных совместных проектах.

OHB System Ag (Германия) - одна из ведущих европейских компаний-интеграторов космических сиамим. Компания почти сорок лет работает со спутни-

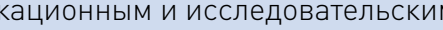
оборудованием, участвует в межпланетных исследов -

В области пилотируемой космонавтики ОНB System Ag также имеет многолетний опыт, участвуя в разработке

Компания QinetiQ

Компания QinetiQ (Бельгия) - главный партнер Асгардии в исследовании и освоении космоса на низ-
ких орбитах. Она поставляет полностью укомплектова ные спутники и основное спутниковое оборудование, включая бортовые компьютеры, блоки удаленных терминалов, блоки массовой памяти, космические механизмы, перспеки-пные электрические силовы установки и приемно-передающие радиостанции. двигают миссию EKA BepiColombo на Меркурий.
После завершения эксплуатации МКС узловой модуль «Асгардия» будет функционировать в качестве основного элемента планируемого «Земного ковчега Асгардии».

интерфейс со всеми меж- сделать партнерство эфдународными партне- фективным с точки зре-
рами (в частности НАСА ния как удовлетворения рами (в частности НАСА ния как удовлетворения
и другими партнерами требований космического MKC), доступ к стыковоч- агентства, так и соотвег сам на европейской части Асгардии.

MKC, включая прочие Реальность такова, что экипажа и технические ряд положительных возконсультации. послеживается по двум K сожалению, несмотря основным категориям. на признание техниче- Первая категория поской обоснованности и по- следствий, известная тенциальных перспектив, как эффект ВвП, касаЕвропейское космическое ется влияния частных агентство на данный мо- инвестиций в разработ ложение консорциума вого модуля учитывая ипотитико-тех- на экономику, поскольнологические» риски. ку ожидается, что частные инвестиции приведут К увеличению Потенциал проекта экономической активно В заключение хоте- сти на всем протяжении лось бы подчеркнуть, что цепочки поставок. официально не признали Учитывая, что проект Асгардию как цифровую стартовал до начала панкосмическую нацию, по- демии COVID-19, нельзя этому политические ри- игнорировать потенциски равны нулю. Техно- алир ио толдержани логические риски также нитости в европейской минимальны, учитывая космической отрасли. тот факт, что членами кон Косм сорциума являются миро- Совокупный эффект втрасли, активно настро- в промышленность, оцеенные на реализациюпро- ниваемый с точки зреекта с целью разработать ния "валовой добавлени построить узловой мо- ной стоимости" (ВДС), дуль "Асгардия" и доста- формирует эффект ВВП. вить его на MKC; к тому же Второе последствие, изАсгардия по-прежнему весное как "каталитиче пребывает в уверенности, ское воздействие», соотчто ресурсы можкно найти ветствует экономической в этом контексте необ- ваемой инфраструктурой В этом контексте необ- вамой инфраструктурой читель мрия усилия, чтобы вым модулем), и связа-

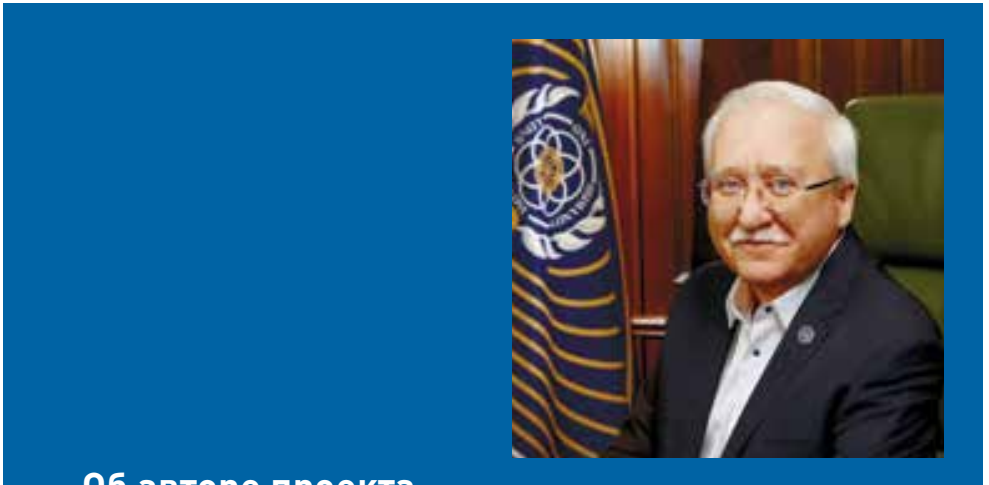

06 авторе проекта

Игорь Рауфович Ашурбейли

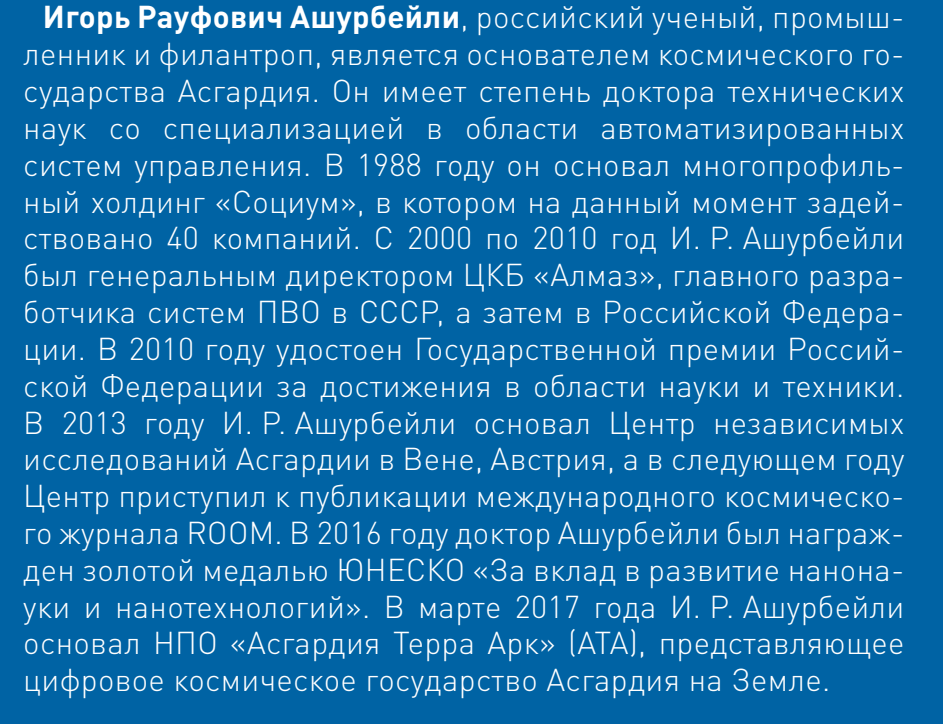

но с валовой выручкой, поот продажи услуг.

прочие услг. и качественные воздействия включают влияние на конкурентоспособность
европейской космической отрасли, на некосмическую экономику и более широки стратегические воздействия, такие как гарантированная занятость, коммерческое по-
зиционирование отрасли и расширение целевых ориентиров MKC

Асгардия занимает активную позицию в плане создания этого партнерства не только из-за очевид-

ной необходимости поддерживать орбитальную ополнения к MKC, но и изза необходимости модернизации европейской части МКС и программ поддержии освоения Луны и Марса.

Основная цель планируе мого партнерства остане ся неизменной. Асгардия считает, что необходим оетенции и, ион и комразделить риски, жеб обеспечить дальнейшее раз итие орбитальной инфраструктуры европейского сообщества в интересах всего человечества.
Литература:

1. Asgardia's project for a new module to expand Space Station // ROOM Space

\section{References} 1. Asgardia's project for a new module to expand
Space Station. ROOM Space Journal of Asgardia, 2020, no. 4, pp. $42-49$
๑ Ашурбейли И.Р., 2021 История статьи: кцию: 12.02 .2021 Модератор: Плетнер К.В.

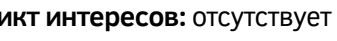
Для цитирования:


ушино-космическая сфера. 2021. № 1. С. $24-33$. 